\title{
Incidence and Risk Factor of Permanent Hypothyroidism in Preterm Infants
}

\section{Mi Lim Chung*}

Departments of Pediatrics, Haeundae Paik Hospital, Inje University College of Medicine, Pusan, Korea

\begin{abstract}
Background: To investigate the incidence and risk factors of permanent hypothyroidism in premature infants diagnosed with congenital hypothyroidism.

Methods: A retrospective review of medical records of preterm infants was performed between March 2010 and December 2013. We included infants who were treated with thyroxine after being diagnosed with congenital hypothyroidism and persistent hyperthyrotropinemia. Exclusion criteria included an infants who were lost to follow up or earlier discontinuation of thyroxine medication and had proven permanent hypothyroidism. We performed trial offtherapy at 36 months of age.

Results: A total of 49 infants were eligible for trial off-therapy at age 3 years. Permanent and transient hypothyroidism was diagnosed in 12 and 37 infants, respectively. Persistent hypothyroidism was more frequent in the infants with high TSH and low FT4 levels at initial screening and high incidence in abnormalities in thyroid imaging work-ups and positive anti-thyroid antibodies. Moreover, the average thyroxine dosage during follow-up was significantly higher in infants with persistent hypothyroidism $(p<0.05)$.

Conclusion: Thyroid dysfunction is common in preterm infants, and nearly $80 \%$ of infants showed transient hypothyroidism. Therefore, if there is no other risk factor for permanent hypothyroidism, it is possible to consider an earlier trail off- therapy for preterm infants.
\end{abstract}

Keywords: Prematurity; Congenital hypothyroidism; Permanent hypothyroidism

Abbreviations: CH: Congenital Hypothyroidism; TFT: Thyroid Function Tests; GA: Gestational Age; NICU: Neonatal Intensive Care Unit; BW: Birth Weight; PDA: Patent Ductus Arteriosus; BPD: Bronchopulmonary Dysplasia; NEC: Necrotizing Enterocolitis; ROP: Retinopathy of Prematurity; TSH: Thyroid Stimulating Hormone; FT4: Free Thyroxine; HT: Hypothyroidism; HTT: Hyperthyrotropinemia; PHT: Permanent Hypothyroidism; THT: Transient Hypothyroidism

\section{Introduction}

Congenital hypothyroidism $(\mathrm{CH})$ is one of the most common endocrine diseases in the pediatric population. Thyroid dysgenesis and less frequently, dyshormonogenesis account for the majority of cases of $\mathrm{CH}$, therefore infants with these underlying causes require lifelong hormonal replacement. However, some of them diagnosed with $\mathrm{CH}$ during the neonatal period have a transient thyroid dysfunction and thus can stop taking medication after a trial off-therapy at around age of 3 years. The incidence of this transient hypothyroidism varies throughout studies, ranging from 35 to $65 \%$ [1-5].

Compared with term neonates, premature infants have a higher incidence of various types of thyroid dysfunction including hypothyroxinemia, hyperthyrotropinemia and $\mathrm{CH}$ [6-8]. Especially, transient thyroid dysfunction is more commonly observed in preterm infants $[9,10]$. Therefore, more many infants are subjected to thyroid hormone supplementation than full term infants and a considerable portion of these prematurity can stop the thyroxine medication. A variety of diagnostic modalities can be used in the newborn infants with a diagnosis of $\mathrm{CH}$, with the thyroid imaging studies such as thyroid ultrasound and thyroid scans. However, these studies are not easily accessible to small premature infants under critical care and they do not usually influence the decision of starting treatment. Thus, thyroid hormone replacement therapy is generally started only based on the results of thyroid function tests (TFTs) without confirmative imaging studies. Therefore, re-evaluation of thyroid function for determining the permanence of hypothyroidism is recommended in all infants in whom the underlying cause of permanent thyroid dysfunction is not identified. However, there are limited data with respect to the incidence of permanent $\mathrm{CH}$ in children who were treated with thyroid hormone after preterm delivery.

The aim of our study is to address the incidence and the risk factor of permanent $\mathrm{CH}$ in preterm infants who were treated with thyroid hormone and had trial off therapy with medical supervision at 36 months of age.

\section{Method}

\section{Subjects and study design}

We performed a retrospective review of medical records in all premature infants (gestational age $(\mathrm{GA})<35$ weeks) who were admitted to the neonatal intensive care unit (NICU) of Haeundae Paik Hospital between March 2010 and October 2013.

We collected the patients' basic demographics including GA, birth weight (BW), sex, Apgar score, mode of delivery and small for gestational age (SGA). Information about morbidities including the

*Corresponding author: Mi Lim Chung, Department of Pediatrics, Haeundae Paik Hospital, Inje University College of Medicine, 875, Haeundae-ro, Haeundae-gu, Pusan, 48108, Korea, Tel: +82-51-797-2000; Fax: +82-51-7971600; E-mail: forevery52@naver.com

Received March 27, 2017; Accepted April 11, 2017; Published April 15, 2017

Citation: Chung ML (2017) Incidence and Risk Factor of Permanent Hypothyroidism in Preterm Infants. J Neonatal Biol 6: 254. doi:10.4172/2167-0897.1000254

Copyright: (C) 2017 Chung ML. This is an open-access article distributed under the terms of the Creative Commons Attribution License, which permits unrestricted use, distribution, and reproduction in any medium, provided the original author and source are credited. 
use of surfactants, patent ductus arteriosus (PDA) requiring ligation surgery or additional therapeutic doses of ibuprofen or indomethacin, bronchopulmonary dysplasia (BPD), necrotizing enterocolitis (NEC), sepsis, retinopathy of prematurity (ROP) requiring laser surgery or intra-vitreal bevacizumab injection were also collected. NEC was defined as stage 2 or greater under the Bell's criteria. BPD was defined by oxygen requirement at 36 weeks of postmenstrual age or 28 days after birth. Culture-proven and clinical sepsis was included. Data regarding the use of thyroid-suppressing medications including metoclopramide, dopamine and aminophylline were collected. In addition, we also collected information about the maternal clinical characteristics and perinatal complications including thyroid disease, medication history, pregnancy-induced hypertension, premature membrane rupture and prenatal steroid treatment.

\section{Subgrouping based on thyroid function tests and trial off- therapy}

All admitted infants were assessed thyroid function according to our protocol. The initial thyroid stimulating hormone (TSH) and free thyroxine (FT4) levels were measured in all neonates within the first week after birth. If the result was normal, routine follow-up tests were performed at 4 weeks of age and prior to discharge. If the result was abnormal, the tests were repeated at 1 to 2 weeks intervals. The reference value for TSH was $<20 \mu \mathrm{U} / \mathrm{mL}$ and that for the free T4 level was $>0.7 \mathrm{ng} / \mathrm{dL}$ at the initial screening, and TSH levels $>9.0 \mu \mathrm{U} / \mathrm{mL}$ after 4 weeks were considered abnormal at the follow up tests [11-13]. The infants who exhibited TSH and free T4 levels within the normal reference ranges in repeated tests and those who exhibited abnormal TSH and free T4 levels but ultimately normalized without medication during the follow-ups were assigned to the "Normal thyroid group". The "Hypothyroid group" included those with hypothyroidism (HT, high TSH and low free T4) and hyperthyrotropinemia (HTT, high TSH and normal free T4) and hypothyroxinemia (normal TSH and low free T4). Our institute administered thyroid hormone to the infants with HT and HTT. The initial thyroxine dosage was $10-15 \mathrm{mcg} / \mathrm{kg} /$ day and was adjusted according to the follow-up TFT results.

At 36 months of age, all thyroxine-treated infants underwent color Doppler thyroid ultrasonography and a technetium (Tc-99 m) thyroid scan. If, the radiologic work-ups revealed no evidence of permanent hypothyroidism (PHT), thyroid hormone replacement was stopped. Subsequently, the patients were monitored and TFTs were performed at 1 and 2 months after the discontinuation of thyroxine medication. According to the results of trial off- therapy at around 36 months of age, PHT was defined by requirement of thyroxine therapy again beyond this period. Likewise, transient hypothyroidism (THT) was defined as no more long-term requirement of thyroxine therapy after the trial offtherapy.

\section{Statistical analysis}

The statistical analyses were performed with SPSS/WIN program version 18.0 (IBM, Amonk, NY, USA). The results were expressed as the mean and median values, and variability is indicated by the standard deviations and/or ranges of values. Continuous data were analyzed using the Student's $t$-test and Mann-Whitney test, and categorical variables were analyzed using the chi-square test or the Fisher's exact test. Result was considered significant when $\mathrm{p}<0.05$.

\section{Results}

A total of 644 preterm infants were admitted to our NICU during the study period. Twenty-two infants were lost to follow up TFTs or expired or transferred to other hospital. 622 infants had completed the repeated thyroid function tests and 87 infants were diagnosed as hypothyroidism. HT, hypothyroxinemia and HTT were diagnosed in 46, 6 and 35 infants, respectively. Except for hypothyroxinemia, 81 infants were treated with thyroxine. Four infants were lost to follow up, and two infants were excluded because they were diagnosed with persistent $\mathrm{CH}$ caused by agenesis of the thyroid gland, as confirmed by thyroid ultrasound and ${ }^{123} \mathrm{I}$ radionuclide imaging. And 26 infants were excluded because of earlier trail off-therapy or stopping medication by self without medical suspension [9]. Finally, 49 infants were eligible for trial off-therapy at 36 months of age. Among the 49 infants who were eligible for the trial off-therapy, $\mathrm{CH}$ and HTT were 29 and 20 cases, respectively. After the trial off-therapy, PHT was diagnosed in 12 (24.5\%) infants and THT was diagnosed in 37 (75.5\%). Infants with transient hypothyroidism had lower GA and birth weights, but it was not significant. There were no differences in basic demographics and clinical characteristics including medications that may affect thyroid function between the two groups (Table 1). Maternal factors also were not different between the two groups (data not shown).

Table 2 shows the results of TFTs and thyroid imaging studies during follow-ups. PHT infants showed a higher incidence of transient hypothyroidism than $\mathrm{CH}(\mathrm{p}<0.05)$. Infants with $\mathrm{PHT}$ had a significant high TSH and low FT4 levels at initial test ( $p$-value $<0.05)$ However, other levels of TSH and FT4 were not different follow-up TFTs except for initial test (data not shown). The average thyroxine dosage during follow up is significantly higher in infants with PHT than THT (p-value $<0.05$ ). In addition, PHT infants had a higher incidence of abnormal thyroid imaging findings and positive anti-thyroid antibody. Abnormal thyroid sonographic finding or thyroid scan were separately associated with the increased risk of PHT (p-value $<0.05)$. Especially, abnormal thyroid radiologic findings were a single most significant risk factor on permanency of hypothyroidism in this present study (Odds ratio: 8.96 with $95 \%$ CI: 2.029-39.561).

\begin{tabular}{|l|c|c|c|}
\hline & Permanent (n=12) & Transient (n=37) & P-value \\
\hline Gestational age (weeks) & $31.38 \pm 2.54$ & $29.96 \pm 2.51$ & 0.09 \\
\hline Birth weight (g) & $1,513.33 \pm 464.61$ & $1,362.97 \pm 388.99$ & 0.27 \\
\hline Sex, male & $3 / 9(25.0 / 75.0)$ & $19 / 18(51.4 / 48.6)$ & 0.11 \\
\hline Delivery type, NSVD & $5(41.7)$ & $11(29.7)$ & 0.44 \\
\hline SGA & $4(33.3)$ & $9(24.3)$ & 0.54 \\
\hline RDS & $5(41.7)$ & $24(64.9)$ & 0.16 \\
\hline Significant PDA & $0(0.0)$ & $5(13.5)$ & 0.18 \\
\hline BPD & $2(16.7)$ & $16(43.2)$ & 0.1 \\
\hline NEC, Bell's stage $\geq 2$ & $2(16.7)$ & $3(8.1)$ & 0.39 \\
\hline HUS & $1(8.3)$ & $9(24.3)$ & 0.23 \\
\hline ROP need treatment & $5(41.7)$ & $25(67.6)$ & 0.11 \\
\hline Sepsis & $3(25.0)$ & $16(43.2)$ & 0.26 \\
\hline Cholestasis & $5(41.7)$ & $16(43.2)$ & 0.18 \\
\hline Metoclopramide & $3(25.0)$ & $16(43.2)$ & 0.38 \\
\hline Dopamine & $3(25.0)$ & $9(24.3)$ & 0.96 \\
\hline Aminophylline & $2(16.7)$ & $0(0.0)$ & 0.16 \\
\hline Values are present) & & \\
\hline
\end{tabular}

Values are presented as $\mathrm{n}(\%)$ or mean $\pm \mathrm{SD}$

NSVD: Normal Spontaneous Vaginal Delivery; SGA: Small for Gestational Age; RDS: Respiratory Distress Syndrome; PDA: Patent Ductus Arteriosus; BPD: Bronchopulmonary Dysplasia; NEC: Necrotizing Enterocolitis; HUS: Head Ultrasonography; ROP: Retinopathy of Prematurity

Table1: Clinical characteristics 


\section{Discussion}

Outcomes of infants with congenital hypothyroidism had remarkably improved after the introduction of nationwide screening program $[14,15]$. In addition to positive effect on prognosis, newborn screening program had allowed identifying transient disorders of thyroid function in infancy [16]. Thus, if permanent underlying cause of hypothyroidism has not been revealed in the newborn period, a confirmation of the diagnosis should be performed about 3 years of ages. However, the incidence of this transient hypothyroidism is varied according to the studies [2-6]. The wide range in reported incidence across the studies might be due to the different diagnostic criteria including cut-off values, endemic load of iodine, re-evaluation policy following initial diagnosis and the enrolled patient's characteristics.

Of the total 49 enrolled infants, 37 (75.5\%) were able to stop the thyroid hormone therapy after a trial off-therapy at 3 years in this study. This result revealed that preterm neonates had a higher incidence of transient thyroid dysfunction compared with full-term infants, and it is consistent with previous reports $[17,18]$. However, lower GA or lower BW did not affect the permanency of thyroid dysfunction, and other clinical factors did not indicate the need for lifelong thyroxine therapy. Among 29 infants diagnosed with congenital hypothyroidism, 10 infants $(34.5 \%)$ had PHT. In contrast, only two infants $(10.0 \%)$ had PHT in 20 infants with diagnosed with persistent HTT (Table 2 , p-value $<0.05)$. This result indicates that these two distinct thyroid dysfunctions including $\mathrm{CH}$ and persistent $\mathrm{HT}$ have a different clinical course. Previous reports also suggests the possibility that HTT might be caused by clinical conditions associated with the preterm birth rather than the abnormality of the thyroid gland itself and therefore infants with persistent HTT showed a higher incidence of transient hypothyroidism after re-evaluation [19-21].

Several imaging studies including thyroid ultrasonography and thyroid scan can determine the underlying causes of hypothyroidism and we can expect the natural course of the thyroid function $[5,22]$. In addition, it can permit parents to be counseled on either the certainty of lifetime therapy. These work ups for etiology of hypothyroidism are

\begin{tabular}{|c|c|c|c|}
\hline Thyroid function Test & Permanent $(n=12)$ & Transient $(\mathrm{n}=37)$ & p-value \\
\hline $\begin{array}{c}\text { Neonatal diagnosis } \\
\text { Congenital hypothyroidism } \\
\text { Persistent } \\
\text { hyperthyrotropinemia }\end{array}$ & $\begin{array}{c}10(34.5) \\
2(10.0)\end{array}$ & $\begin{array}{l}19(65.5) \\
18(90.0)\end{array}$ & 0.04 \\
\hline $\begin{array}{c}\text { TSH and FT4 levels at initial } \\
\text { test TSH }(\mathrm{mU} / \mathrm{L}) \\
\text { FT4 }(\mathrm{ng} / \mathrm{dL})\end{array}$ & $\begin{array}{c}16.85 \pm 9.70 \\
1.14 \pm 0.23\end{array}$ & $\begin{array}{l}6.76 \pm 5.89 \\
1.41 \pm 0.22\end{array}$ & $\begin{array}{l}<0.01 \\
<0.01\end{array}$ \\
\hline $\begin{array}{c}\text { TSH and FT4 levels at the time } \\
\text { of hormone replacement } \\
\text { TSH }(\mathrm{mU} / \mathrm{L}) \\
\text { FT4 }(\mathrm{ng} / \mathrm{dL})\end{array}$ & $\begin{aligned} 42.64 & \pm 32.57 \\
0.75 & \pm 0.20\end{aligned}$ & $\begin{array}{c}34.96 \pm 31.83 \\
0.94 \pm 0.33\end{array}$ & $\begin{array}{l}0.48 \\
0.07\end{array}$ \\
\hline $\begin{array}{l}\text { Average thyroxine dosage } \\
(\mathrm{mcg} / \mathrm{kg})\end{array}$ & $5.68 \pm 1.39$ & $3.77 \pm 0.74$ & $<0.01$ \\
\hline $\begin{array}{l}\text { Anti-thyroid antibody test } \\
(\mathrm{N}=37) \\
\text { Positive }(9) \\
\text { Negative }(30)\end{array}$ & $\begin{array}{l}7 \\
5\end{array}$ & $\begin{array}{c}2 \\
25\end{array}$ & $<0.01$ \\
\hline $\begin{array}{l}\text { Thyroid imaging studies } \\
\text { 1. Thyroid ultrasonography } \\
(\mathrm{N}=49) \\
\text { Normal }(7) \\
\text { Abnormal (42) }\end{array}$ & $\begin{array}{l}5 \\
7\end{array}$ & $\begin{array}{c}2 \\
35\end{array}$ & 0.01 \\
\hline $\begin{array}{l}\text { 2. Thyroid scan }(\mathrm{N}=42) \\
\text { Normal }(6) \\
\text { Abnormal (12) }\end{array}$ & $\begin{array}{l}5 \\
7\end{array}$ & $\begin{array}{c}4 \\
26\end{array}$ & \\
\hline
\end{tabular}

Table 2: Thyroid function test results. more important in preterm infants because transient hypothyroidism is common due to more frequent exposure to non-thyroidal illness and medications that can suppress the thyroid function. However, prompt initiation of thyroxine therapy in neonates with either $\mathrm{CH}$ or persistent HTT often prevents the performance of functional studies of thyroid gland. Etiologic work up for underlying cause of hypothyroidism is thus postponed until after infancy. Moreover, thyroid function test results or thyroid radiologic work-up findings could not alone distinguish the PHT from the THT. Therefore, all infants who were treated with thyroid hormone should receive a trial off- therapy except for those with confirmed thyroid agenesis after 3 years of age. However, 36months-long which is recommended in current guidelines for $\mathrm{CH}$ is too long for parent to follow up routinely and force to take medicine for infant. According to the report by Kemper et al. [23], more than onethird of children treated for congenital hypothyroidism discontinued medication before 36 months of age in the United States. Of course, it is not known how many of these children required continued treatment or experience adverse effects from discontinuation. Therefore, in the meantime, there have been many efforts to predict the permanence of thyroid dysfunction [24-28]. This study suggests that abnormal thyroid imaging study, needs to escalate the thyroxine dosage for adjusting normal TFT during follow up, positive anti-thyroid antibody, high TSH and low FT4 levels at initial test ( the exact value is not determined, yet), $\mathrm{CH}$ rather than persistent HTT are the significant risk factor for PHT. Some of our study's findings are consistent with the previous studies [24-27]. Moreover, it is possible that infants who had no or fewer risk factors mentioned before are candidates for early trial off-therapy $[29,30]$.

\section{Limitations}

This study has several limitations. First, this study is retrospective study. Therefore, there are lots of people who had lost to followup and laboratory and radiologic work ups were not uniformly applied in enrolled infants. Second, other outcomes including neurodevelopmental achievement was not evaluated. And currently, there is no specific guideline in whether treatment is needed or when to start the medication of persistent HTT of preterm infants. Therefore, our unit protocol for diagnosis, treatment and re-evaluation was not fully evidence-based.

\section{Conclusion}

This study shows the high incidence of THT and determines several risk factors for permanency of thyroid dysfunction in preterm infants. Therefore, earlier re-evaluation for considering of stopping thyroxine medication can be feasible in low-risk premature infants. And finally, specified guidelines for the diagnosis, treatment and follow-up for prematurity can be expected in the future.

\section{Acknowledgement}

This work was supported by Grant from Inje University, 2011.

\section{References}

1. Deladoëy J, Ruel J, Giguère $Y$, Van Vliet $G$ (2011) Is the incidence of congenital hypothyroidism really increasing? A 20 year retrospective population-based study in Québec. J Clin Endocrinol Metab 96: 2422-2429.

2. Mitchell ML, Hsu HW, Sahai I; Massachusetts Pediatric Endocrine Work Group (2011) The increased incidence of congenital hypothyroidism: Fact or fancy? Clin Endorinol (Oxf) 75: 806-810.

3. Korzeniewski SJ, Grigorescu V, Kleyn M, Young WI, Birbeck G et al (2013) Transient hypothyroidism at 3-year follow-up among cases of congenital hypothyroidism detected by new-born screening. J Pediatr 162: 177-182.

4. Hinton CF, Harris KB, Borgfeld L, Drummond-Borg M, Eaton R, et al. (2010) 
Citation: Chung ML (2017) Incidence and Risk Factor of Permanent Hypothyroidism in Preterm Infants. J Neonatal Biol 6: 254. doi:10.4172/21670897.1000254

Trends in incidence rates of congenital hypothyroidism related to select demographic factors: Data from the United States, California, Massachusetts, New York and Texas. Pediatrics 125: S37-47.

5. Bhavani N (2011) Transient congenital hypothyroidism. Indian J Endocrinol Metab 15: S117-120.

6. Radetti G, Fanolla A, Pappalardo L, Gottardi E (2007) Prematurity may be a risk factor for thyroid dysfunction in childhood. J Clin Endocrinol Metab 92: 155-159.

7. Delange F, Dalhem A, Bourdoux P, Lagasse R, Glinoer D, et al. (1984) Increased risk of primary hypothyroidism in preterm infants. J Pediatr 105: 462-469.

8. Fisher DA (2007) Thyroid function and dysfunction in premature infants. Pediatr Endocrinol Rev 4: 317-328.

9. Chung HR, Shin $\mathrm{CH}$, Yang SW, Choi CW, Kim BI, et al. (2009) High incidence of thyroid dysfunction in preterm infants. J Korean Med Sci 24: 627-631.

10. Jung JM, Jin HY, Chung ML (2016) Feasibility of an early discontinuation of thyroid hormone treatment in very-low-birth-weight infants at risk for transient or permanent congenital hypothyroidism. Horm Res Paediatr 85: 131-139.

11. Lim G, Lee YK, Han HS (2014) Early discontinuation of thyroxine therapy is possible in most very low-birthweight infants with hypothyroidism detected by screening. Acta Paediatr 103: e123-129.

12. American Academy of Pediatrics; Section on Endocrinology and Committee on Genetics; American Thyroid Association; Public Health Committee; Lawson Wilkins Pediatric Endocrine Society; Brown RS; Rose SR, et al. (2006) Update of new-born screening and therapy for congenital hypothyroidism. Pediatrics 117: 2290-2303.

13. Sperling MA (2014) Pediatric endocrinology. (4th edn), Saunders, Philadelphia.

14. Fisher DA, Dussault JH, Foley TP Jr, Klein AH, LaFranchi S, et al. (1979) Screening for congenital hypothyroidism: results of screening one million North American infants. J Pediatr 94: 700-705.

15. Kurinczuk JJ, Bower C, Lewis B, Byrne G (2002) Congenital hypothyroidism in Western Australia 1981-1998. J Paediatr Child Health 38: 187-191.

16. Olivieri A, Fazzini C, Medda E; Italian Study Group for Congenital Hypothyroidism (2015) Multiple factors influencing the incidence of congenital hypothyroidism detected by neonatal screening. Horm Res Paediatr 83: 86-93.

17. Srinivasan R, Harigopal S, Turner S, Cheetham T (2012) Permanent and transient congenital hypothyroidism in preterm infants. Acta Paediatr 101: e179-182.

18. Vigone MC, Caiulo S, Di Frenna M, Ghirardello S, Corbetta C, et al. (2014) Evolution of thyroid function in preterm infants detected by screening for congenital hypothyroidism. J Pediatr 164: 1296-1302.
19. Woo HC, Lizarda A, Tucker R, Mitchell ML, Vohr B, et al. (2011) Congenital hypothyroidism with a delayed thyroid-stimulating hormone elevation in very premature infants: Incidence and growth and developmental outcomes. J Pediatr 158: 538-542.

20. Chung ML, Yoo HW, Kim KS, Lee BS, Pi SY, et al. (2013) Thyroid dysfunctions of prematurity and their impacts on neurodevelopmental outcome. J Pediatr Endocrinol Metab 26: 449-455.

21. Zung A, Tenenbaum-Rakover Y, Barkan S, Hanukoglu A, Hershkovitz E, et al (2010) Neonatal hyperthyrotropinemia: Population characteristics, diagnosis, management and outcome after cessation of therapy. Clin Endocrinol (Oxf) 72: 264-271.

22. Schoen EJ, Clapp W, To TT, Fireman BH (2004) The key role of new-born thyroid scintigraphy with isotopic iodide (123I) in defining and managing congenital hypothyroidism. Pediatrics 114: e683-688.

23. Kemper AR, Ouyang L, Grosse SD (2010) Discontinuation of thyroid hormone treatment among children in the United States with congenital hypothyroidism: Findings from health insurance claims data. BMC Pediatr 10: 9.

24. Gaudino R, Garel C, Czernichow P, Léger J (2005) Proportion of various type of thyroid disorders among newborns with congenital hypothyroidism and normally located gland: A regional cohort study. Clin Endocrinol (Oxf) 62: 444448.

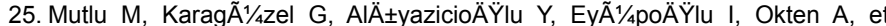
al. (2012) Reference intervals for thyrotropin and thyroid hormones and ultrasonographic thyroid volume during the neonatal period. J Matern Fetal Neonatal Med 25: 120-124.

26. Cho MS, Cho GS, Park SH, Jung MH, Suh BK, et al. (2014) Earlier re-evaluation may be possible in pediatric patients with eutopic congenital hypothyroidism requiring lower L-thyroxine doses. Ann Pediatr Endocrinol Metab 19: 141-145.

27. Hong SY, Chung HR, Lee SY (2005) Factors distinguishing between transient and permanent hypothyroidism in patients diagnosed as congenitalhypothyroidism by newborn screening. J Korean Soc Pediatr Endocrinol 10: 154-160.

28. Rabbiosi S, Vigone MC, Cortinovis F, Zamproni I, Fugazzola L, et al. (2013) Congenital hypothyroidism with eutopic thyroid gland: analysis of clinical and biochemical features at diagnosis and after re-evaluation. J Clin Endocrino Metab 98: 1395-1402.

29. Lim HK, Kim KH, Kim SH, No HY, Kim CJ, et al. (2006) Predictors of transient hypothyroidism in neonatal screening test. J Korean Soc Pediatr Endorinol 11 $50-56$

30. Unüvar T, Demir K, Abaci A, Büyükgebiz A, Böber E, et al. (2013) The role of initial clinical and laboratory findings in infants with hyperthyrotropinemia to predict transient or permanent hypothyroidism. J Clin Res Pediatr Endocrino 10: $170-173$ 